\title{
Balance of optical, structural and electrical properties of textured liquid phase crystallized Si solar cells
}

\author{
V. Preidel ${ }^{\text {a) }}$, D. Amkreutz, J. Haschke, M. Wollgarten, B. Rech, and C. Becker \\ Helmholtz-Zentrum Berlin für Materialien und Energie GmbH, Division Renewable Energy, \\ Kekuléstr. 5, 12489 Berlin, Germany
}

Liquid phase crystallized Si thin-film solar cells on nanoimprint textured glass substrates exhibiting two characteristic, but distinct different surface structures are presented. The impact of the substrate texture on light absorption, the structural Si material properties and the resulting solar cell performance is analyzed. A pronounced periodic substrate texture with a vertical feature size of about $1 \mu \mathrm{m}$ enables excellent light scattering and light trapping. However, it also gives rise to an enhanced Si crystal defect formation deteriorating the solar cell performance. In contrast, a random pattern with a low surface roughness of $45 \mathrm{~nm}$ allows for the growth of Si thin films being comparable to Si layers on planar reference substrates. Amorphous Si/crystalline Si heterojunction solar cells fabricated on the low-roughness texture exhibit a maximum open circuit voltage of $616 \mathrm{mV}$ and internal quantum efficiency peak values exceeding 90\% resulting in an efficiency potential of $13.2 \%$. This demonstrates that high quality crystalline Si thin films can be realized on nanoimprint patterned glass substrates by liquid phase crystallization inspiring the implementation of tailor-made nanophotonic light harvesting concepts into future liquid phase crystallized Si thin film solar cells on glass.

\section{INTRODUCTION}

The present-day photovoltaic market is dominated by solar cell devices based on multicrystalline Si wafers. Liquid phase crystallization (LPC) of Si thin films on glass represents a promising alternative technology as it allows reducing the Si usage by more than a factor of 10. Just recently, 10 micrometer thin LPC Si solar cells were realized yielding open circuit voltages up to $656 \mathrm{mV}$, being comparable with the open circuit voltage of record multicrystalline Si wafer devices. ${ }^{1,2}$ So far, the maximum conversion efficiency of LPC Si solar cells is limited to $11.8 \%{ }^{3,4}$ Incomplete light absorption has been identified as one major efficiency-limiting factor. Dore et al. have addressed this issue by randomly texturing the rear side of the Si

absorber. ${ }^{5}$ Nevertheless, in order to increase efficiencies towards $16 \%$ and beyond, a light harvesting concept has to be implemented that features both, a patterned front and patterned rear side, reducing the reflectivity and providing light trapping inside the Si absorber layer. Inspired by amorphous or solid phase crystallized Si thin-film solar cell technologies commonly using structured substrates for light trapping ${ }^{6,7}$, we recently presented a process to realize double-sided textured LPC Si thin-films on nanoimprint patterned glass substrates. ${ }^{8}$ This approach enables a systematic tailoring of the topography of the Si thin film by adjusting the nanoimprint template which can be designed in nearly arbitrary geometry. A high optical

\footnotetext{
a Electronic mail: veit.preidel@helmholtz-berlin.de
} 
absorption approaching the lambertian limit was reached. However, the resulting solar cell efficiency was limited to $8.1 \%$ with a corresponding open circuit voltage of $553 \mathrm{mV}$ indicating a deterioration of the electrical absorber quality caused by the high aspect ratio substrate pattern used in this case. Therefore, an in-depth understanding on the impact of a certain substrate texture on the LPC process and the resulting Si material quality is indispensable.

Here in this paper, we present a detailed analysis of the correlation of the substrate texture and the resulting optical, structural and electronic material quality of LPC Si thin films. We used a focussed electron beam for LPC of Si thin films on a high aspect ratio periodic texture, a low surface roughness random texture and a planar glass substrate as model systems. For this purpose we characterized the structural Si material quality by cross-sectional TEM and defect etching and connected it to the electrical material properties, which were assessed by characterizing amorphous Si/crystalline Si heterojunction solar cells. At the same time we investigated the optical absorption in order to evaluate the light harvesting performance. Doing so the interplay of the optical, structural and electrical material properties was analyzed providing design rules for the growth of high quality Si on glass.

\section{METHODS AND MATERIALS}

\section{A. Realization of nanoimprint patterned substrates}

$10 \times 5 \mathrm{~cm}^{2}$ Corning Eagle XG glasses (1.1 mm thick) were cleaned using an alkaline based general purpose cleaner (Mucasol) and dip-coated with an UV-curable alkoxysilane based hybrid-polymer sol-gel solution. ${ }^{9}$ Structuring of the sol-gel layer was performed by UV-nanoimprint lithography using polydimethylsiloxane (PDMS) molds that have been fabricated by casting PDMS solution over a master structure. After the imprinting process UV and thermal curing $\left(500^{\circ} \mathrm{C}, 1 \mathrm{~h}\right)$ were applied to achieve crosslinking, decompose the organic residues and densify the sol-gel network resulting in a high temperature stable structured glassy surface. Two different types of substrate textures were realized: (1) A 2 pm periodic ushaped square lattice pattern with a valley-to-peak height of $1.0-1.3 \mu \mathrm{m}$ and a feature width of $0.6 \mu \mathrm{m}$ (at half height). This texture is depicted in Figure 1 (a) and will in the following be referred to as the pronounced texture. The respective master consisting of a nickel shim had been fabricated at Fraunhofer ISE, Germany, using interference lithography. (2) A random texture exhibiting a root mean square roughness $R_{\mathrm{rms}}$ of $45 \mathrm{~nm}$ and characteristical lateral crater dimensions of 1-2 $\mu \mathrm{m}$. This texture is illustrated in Figure 1 (d) and will be termed the moderate texture. Here, the respective PDMS mold was fabricated using a commercially available textured $\mathrm{ZnO}$ :Al layer on glass (master structure), which had been deposited by magnetron sputtering and textured by hydrochloric acid. ${ }^{10}$ The master structure exhibited a $R_{\mathrm{rms}}$ of $125 \mathrm{~nm}$. The large differences of the $R_{\mathrm{rms}}$ of the imprinted substrate texture and of the master structure can be attributed to shrinking of the sol-gel resist during the thermal curing. 

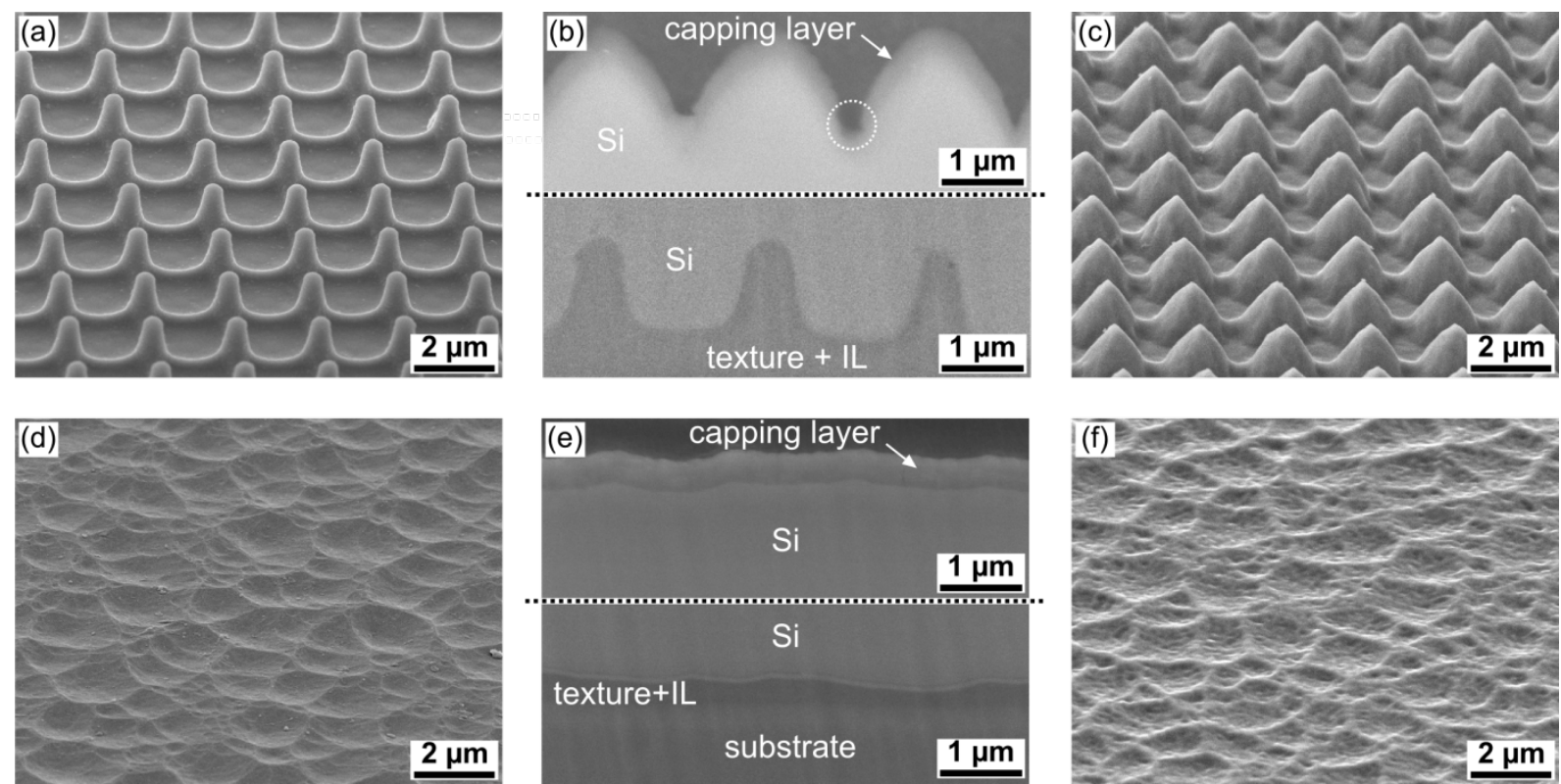

FIG. 1. SEM micrographs of the pronounced periodic (a) and the moderate random sol-gel texture (d). Cross-sectional (b, e) and top-view SEM images (c, f) of $10 \mu \mathrm{m}$ thick liquid phase crystallized Si thin films prepared on the respective texture.

\section{B. Preparation of the absorber layer}

Textured and planar substrates were coated with a multifunctional intermediate layer stack using reactive magnetron sputtering. This layer stack consisted of 200-300 nm $\mathrm{SiO}_{\mathrm{x}}, 80 \mathrm{~nm} \mathrm{SiN}_{\mathrm{x}}$ and 10-20 nm $\mathrm{SiO}_{\mathrm{x}}$ acting as diffusion barrier, antireflection coating and front side passivation respectively. Subsequently $10 \mu \mathrm{m}$ of nominally intrinsic nanocrystalline (nc) Si were deposited by e-beam evaporation at a rate between $500 \mathrm{~nm} / \mathrm{min}$ and $600 \mathrm{~nm} / \mathrm{min} .{ }^{11}$ As a dopant source a $2-3 \mathrm{~nm}$ thin layer of n-doped $\left(1 \times 10^{20} \mathrm{~cm}^{-3}\right)$ hydrogenated amorphous silicon (a-Si:H) was deposited on top of the nc-Si using plasma enhanced chemical vapor deposition and annealed at $600{ }^{\circ} \mathrm{C}$ for $6 \mathrm{~h}$ under nitrogen atmosphere in order to remove hydrogen. Subsequently a 300-500 $\mathrm{nm}$ thick $\mathrm{SiO}_{\mathrm{x}}$ capping layer was deposited on top of the layer stack by reactive magnetron sputtering. The capping layer fulfils two functions: (1) It inhibits dewetting of the liquid Si thin film due the relaxation of the wetting angle constraints. ${ }^{12,13}$ (2) It prevents the surface of the Si melt from levelling out and thus allows maintaining the initial topography of the as deposited layer. ${ }^{8}$ Due to the directional characteristics of magnetron sputter deposition both the intermediate layers and the capping layer are non-conformal. At the steep flanks of the pronounced substrate texture e. g. the intermediate layer thickness is reduced by about $20 \%$ compared to the layer thickness on top and in between the sol-gel features. For the pronounced texture vertical voids inside the capping layer at the v-shaped grooves between two adjacent $\mathrm{Si}$ domes can be observed prior to the crystallization process (not shown here). At some of these spots a partial ablation of the capping layer during the crystallization process takes place (see circle in Figure 1 (b)). In the next step the Si is liquid phase crystallized using a line focussed e-beam at a constant scanning speed of $6 \mathrm{~mm} / \mathrm{s}$ and an energy of around $1 \mathrm{~J} / \mathrm{mm}^{2}$ resulting in lateral crystal growth. ${ }^{14}$ No dependence of the crystallization parameters on the type of substrate has been observed. The 
dopant concentration of the Si absorber layer was $2 \times 10^{17} \mathrm{~cm}^{-3}$. To reduce internal stress rapid thermal annealing with a $60 \mathrm{~s}$ plateau at $950{ }^{\circ} \mathrm{C}$ was applied after the LPC process. Subsequently the $\mathrm{SiO}_{\mathrm{x}}$ capping layer and defect-rich $\mathrm{Si}$ material at the surface stemming from the LPC process were removed using a buffered oxide and $\mathrm{HNO}_{3} / \mathrm{H}_{3} \mathrm{PO}_{4}$-based etchant. Afterwards a hydrogen plasma treatment at $600^{\circ} \mathrm{C}$ and 1,0 mbar was applied for 15 min followed by a second Si etching process in order to remove plasma damaged material. ${ }^{13,15}$ Subsequently, a RCA standard cleaning procedure was conducted. pn-heterojunctions were formed by depositing a $5 \mathrm{~nm}$ thick intrinsic hydrogenated amorphous $\mathrm{Si}$ (a-Si:H) buffer and a $10 \mathrm{~nm}$ thick p-doped aSi:H emitter layer. Figure 1 depicts cross-sectional SEM micrographs of the surface and interface area of the as crystallized layer stack on the pronounced (b) and the moderate substrate texture (e). Figure 1 (c) and (f) show the respective Si surface after the $\mathrm{SiO}_{\mathrm{x}}$ capping layer has been removed.

\section{Device fabrication}

Based on this layer stacks we prepared solar cell devices. In the case of the moderate substrate texture and the planar reference substrate we prepared test devices using a very simple and quick fabrication process featuring an $8 \mathrm{~mm}$ x $8 \mathrm{~mm}$ large indium tin oxide (ITO) emitter contact pad and a Ti/Pd/Ag absorber contact placed outside the ITO coated emitter area. In the case of the pronounced texture we fabricated back contacted silicon heterojunction solar cells with an area of $10 \mathrm{~mm} x$ $6 \mathrm{~mm}$, using an ITO emitter contact layer and Ti/Pd/Ag emitter and absorber contact grids. Finally a $1 \mathrm{~mm}$ thick layer of white paint (Tipp-Ex® ECOLUTIONS -Aqua) was applied on top of the layer stack acting as a diffusive rear reflector. For further details on the device structures and the respective preparation processes the reader is referred to the work of Haschke et al.. ${ }^{1,16}$

\section{Characterization}

Absorption and reflection spectra were measured with a LAMBDA 1050 Perkin Elmer UV/VIS/NIR spectrometer. The samples were mounted in the centre of a $150 \mathrm{~mm}$ integrating sphere, tilted by $8^{\circ}$ with respect to the probe beam and illuminated from the glass side.

In order to investigate the absorption enhancement due to the surface patterning without having to consider parasitic absorption layer stacks without the a-Si:H(i) buffer, the a-Si:H(p) emitter and without contact layers were used for optical characterization. Furthermore a thin diffusive $\mathrm{BaSO}_{4}$ rear reflector (OptoPolymer) exhibiting low absorption $(<2 \%)$ was applied on theses samples by spray coating.

For reflection measurements a cardboard coated with black paint was attached to the rear side of the sample, absorbing the transmitted light. Hereby only the reflected light reaches the detector. For microscopical analysis a Carl Zeiss Libra 200FE transmissions electron microscope (TEM) and a Hitachi cold field emitter scanning electron microscope (SEM) in 
combination with an EDAX/TSL electron backscatter diffraction (EBSD) setup were used. $30 \mathrm{~nm}$ to $40 \mathrm{~nm}$ thick TEM lamellae were prepared by mechanical polishing and ion milling. The external quantum efficiency was measured with a custom-made setup, exhibiting a probe beam with a spot size of $3 \mathrm{~mm}$ x $2 \mathrm{~mm}$. Suns $\mathrm{V}_{\text {ос }}$ measurements were conducted at room temperature using a Suns $\mathrm{V}_{\text {oc }}$ setup from Sinton Instruments with a WCT-100 photoconductance lifetime tool. For the determination of the optical properties one sample of each type was analyzed. For the characterization of the device parameters multiple samples were measured.

\section{RESULTS}

\section{A. Optical properties}

Figure 2 depicts the absorption $\mathrm{A}$ and reflection $\mathrm{R}$ of $10 \mu \mathrm{m}$ thick liquid phase crystallized Si thin films on the moderate substrate texture, the pronounced substrate texture and on a planar substrate. As a reference an approximation of the lambertian limit $A_{\text {lamb }}$ for a $10 \mu \mathrm{m}$ thick Si layer is shown assuming zero front side reflection and an ideal rear reflector. ${ }^{17}$ While the absorption of the moderately textured Si thin film coincides with the absorption of the planar Si thin film for wavelengths below $700 \mathrm{~nm}$, a moderate, but significant increase compared to the planar reference can be observed for wavelengths above $800 \mathrm{~nm}$. In contrast, the Si layer on the pronounced substrate texture exhibits a very strong absorption enhancement in the long wavelength range above $600 \mathrm{~nm}$ and in addition also an increase of absorption in the short wavelength range below $450 \mathrm{~nm}$. In the case of the moderate substrate texture no impact of the structured surface on the antireflection properties can be observed. The absorption enhancement can mainly be attributed to enhanced internal reflection. In the case of the pronounced texture, however, the absorption enhancement is due to both a reduced front side reflectivity and increased internal reflection. Non-vanishing absorption below the Si bandgap can be attributed to parasitic absorption at and in the white paint rear reflector. The light harvesting performance of the investigated model systems was evaluated by calculating the maximum achievable short circuit current density $J_{\text {sc,max }}$ according to the equation

$$
J_{s c, \max }=q \int_{300 \mathrm{~nm}}^{1100 \mathrm{~nm}} \frac{\mathrm{s}(\lambda) \cdot \mathrm{A}(\lambda) \cdot \lambda}{\mathrm{h} \cdot \mathrm{c}} \mathrm{d} \lambda
$$

where $\mathrm{q}$ corresponds to the elementary charge, $h c / \lambda$ to the photon energy, $\mathrm{S}(\lambda)$ to the solar irradiance of the AM1.5 global reference spectrum and $\mathrm{A}(\lambda)$ to the experimentally determined absorption. The moderate substrate texture yields a $J_{\mathrm{sc} \text {,max }}$ of $32.0 \mathrm{~mA} / \mathrm{cm}^{2}$ and the pronounced texture a $J_{\mathrm{sc} \text {,max }}$ of $36.3 \mathrm{~mA} / \mathrm{cm}^{2}$ corresponding to a $6 \%$ and $20 \%$ increase respectively compared to the planar reference which yields a $J_{\mathrm{sc}, \max }$ of $30.2 \mathrm{~mA} / \mathrm{cm}^{2}$. Using the lambertian limit a $J_{\mathrm{sc}, \mathrm{max}}$ of $39.7 \mathrm{~mA} / \mathrm{cm}^{2}$ is obtained. When comparing the light harvesting performance the presented Si thin films to the lambertian limit it has to be taken into account that roughly $4 \%$ of the incoming light are reflected at the air/glass interface and thus the light harvesting properties are underestimated. This holds especially for the short wavelength range between $300 \mathrm{~nm}$ and $600 \mathrm{~nm}$ where the 
film absorption is mainly governed by the reflection properties. However, regarding a future optimized device reflection at the air/glass interface losses can easily be eliminated using standard broadband antireflection coatings.

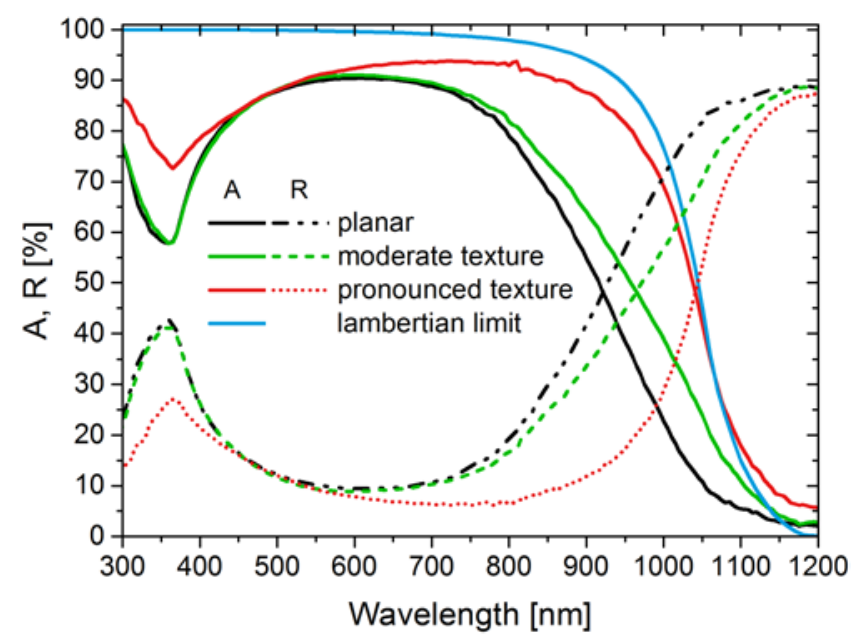

FIG. 2. Optical absorption A and reflection R of $10 \mu \mathrm{m}$ thick liquid phase crystallized Si thin films on a planar glass (black), the moderate random substrate texture (green) and the pronounced periodic substrate texture on glass (red) along with the corresponding lambertian limit (blue). All samples exhibited a $\mathrm{SiN}_{\mathrm{x}}$ antireflection coating between the substrate and the Si thin film and a dispersive $\mathrm{BaSO}_{4}$ white paint rear reflector.

\section{B. Structural properties}

When evaluating Si thin films for an application as absorber layers in solar cells it is indispensable to consider both the optical properties and the structural and electrical material quality. The structural material quality was investigated by EBSD surface orientation maps, cross-sectional TEM analysis and defect etching of the as crystallized Si surface using a Secco etch solution. $^{18}$

Figure 3 shows typical EBSD surface orientation mappings of $\mathrm{Si}$ thin films with a $\mathrm{SiO}_{\mathrm{x}} / \mathrm{SiN}_{\mathrm{x}} / \mathrm{SiO}_{\mathrm{x}}$ intermediate layer stack on the moderate texture (a), the pronounced texture (b), and on a planar glass substrate (c). The respective images consist of several individual mappings as indicated by the dashed lines. The grain structures of the Si thin films on the moderate texture and on the planar substrate resemble each other exhibiting elongated grains of several millimetres in length. In contrast, in the case of the Si thin film on the pronounced texture agglomerations of grains with reduced sizes in between large elongated grains can be observed. 

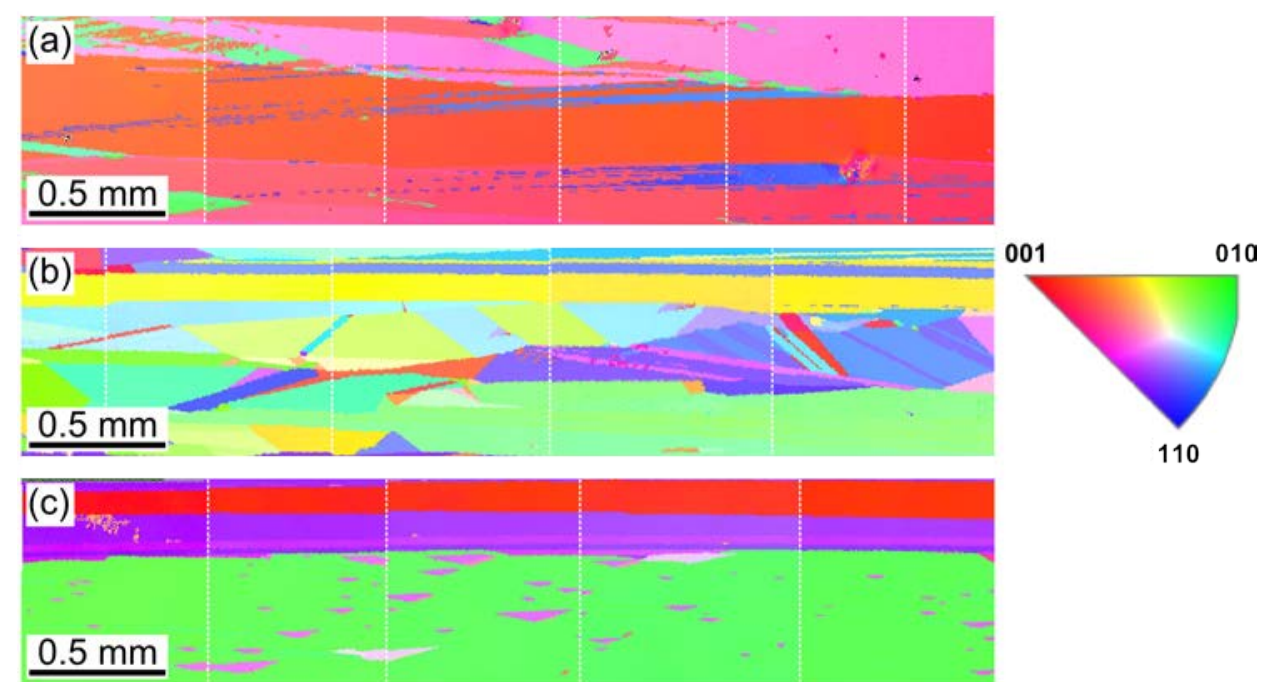

FIG. 3. EBSD surface orientation maps of LPC Si thin films on the moderate substrate texture (a), the pronounced substrate texture (b) and on a planar substrate (c). The color coding of the different crystallographic orientations is depicted on the right hand side.

Figure 4 depicts representative TEM micrographs of the interface area of LPC Si thin films on the pronounced texture with a $50 \mathrm{~nm}$ thick $\mathrm{SiO}_{\mathrm{x}}$ intermediate layer (a) and on the moderate texture with the above described $\mathrm{SiO}_{\mathrm{x}} / \mathrm{SiN}_{\mathrm{x}} / \mathrm{SiO}_{\mathrm{x}}$ intermediate layer stack (c). In the case of the pronounced substrate texture multiple diffraction features which can be attributed to dislocations in the Si crystal can be observed close to the interface (red circles). A close-up view (green rectangle) of two dislocation related diffraction lines, identifiable by their characteristic well defined and a diffuse edges, is depicted on the right hand side of Figure 4 (a). On the contrary, TEM micrographs of the Si layer on the moderate texture exhibit no dislocation contrasts. Figure 4 (b) and (d) show typical SEM micrographs of the defect etched surface of LPC Si thin-films on the pronounced and the moderate texture respectively. In the case of the pronounced substrate texture all examined spots of the sample exhibited agglomerations of etch pits. They are preferentially located on top of the respective Si domes (red circles). SEM analysis of the defect etched Si thin film on the moderate texture mainly yields etch pit-free areas being comparable to the surface of a planar reference layer (not shown here). The defect-etched line-feature in Figure 4 (d) corresponds to a grain boundary and thus demonstrates that the etching process itself has been performed successfully. Hence, both the TEM and the defect etch analysis show that the density of structural defects is significantly higher for the pronounced texture than for the moderate one. 

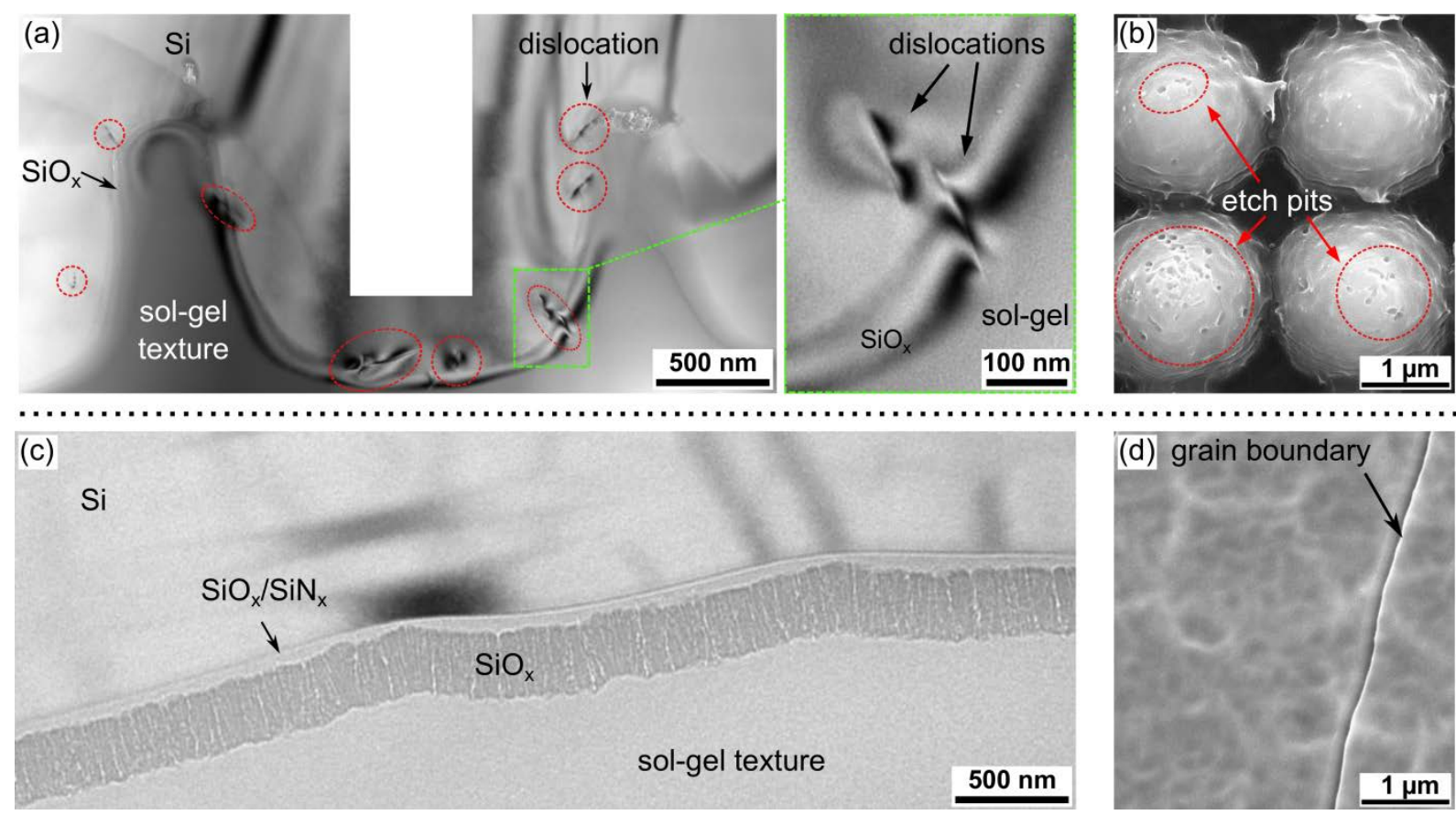

FIG. 4. TEM micrographs of interface area of LPC Si thin films on the pronounced periodic texture with a $50 \mathrm{~nm}$ thick $\mathrm{SiO}$ diffusion barrier (a) and on the moderate random texture with $\mathrm{SiO}_{\mathrm{x}} / \mathrm{SiN}_{\mathrm{x}} / \mathrm{SiO}_{\mathrm{x}}$ intermediate layer stack (c). The SEM micrographs (b) and (d) depict the respective defect etched Si surface.

\section{Electrical properties}

Figure 5 depicts the external quantum efficiency EQE of solar cell devices fabricated on the pronounced and the moderate texture and on a planar substrate along with the respective absorption A. Figure 6 shows the corresponding internal quantum efficiency $\mathrm{IQE}_{\mathrm{A}}$ which has been determined by normalizing the EQE by the respective absorption. Parasitic absorption due to the ITO contact layer, the rear reflector and in the case of the pronounced texture also the metal contact grid leads to an overestimation of the $\mathrm{IQE}_{\mathrm{A}}$ for $\lambda>650 \mathrm{~nm}$ becoming more pronounced as the wavelength increases (dotted lines). For $\lambda<650 \mathrm{~nm}$ parasitic absorption on the rear side of the solar cell can be neglected. Hence, in this wavelength range the $\mathrm{IQE}_{\mathrm{A}}$ represents a measure of the electrical material properties including bulk as well as surface recombination processes.

Inspecting the EQE of the solar cell on the pronounced texture we observe a strong decrease compared to the EQE of the solar cell on the planar substrate (up to a factor of 4), even though the respective absorption properties are superior throughout most of the spectral range. In contrast the EQE of the solar cell on the moderate texture coincides with the EQE of the planar reference cell up to wavelengths of about $850 \mathrm{~nm}$ and exceeds it above this wavelength. The latter can be attributed to the increased absorption due the surface texturing. Comparable internal quantum efficiency peak values of around $90 \%$ are obtained for both the solar cell on the moderate substrate texture and the planar substrate, reflecting a high electrical material quality. In contrast the $\mathrm{IQE}_{\mathrm{A}}$ of the solar cell device on the pronounced substrate texture proceeds on a very low level ( $<28 \%$ for $\lambda<650 \mathrm{~nm}$ ) indicating an enhanced carrier recombination. 


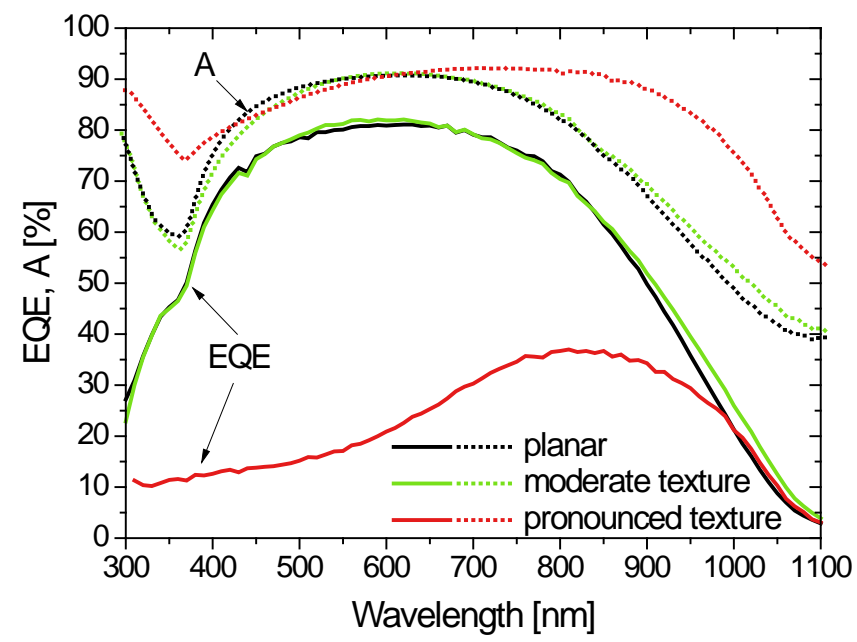

FIG. 5. Absorption (A) and external quantum efficiency (EQE) of solar cell devices fabricated on planar glass, the moderate and the pronounced substrate texture.

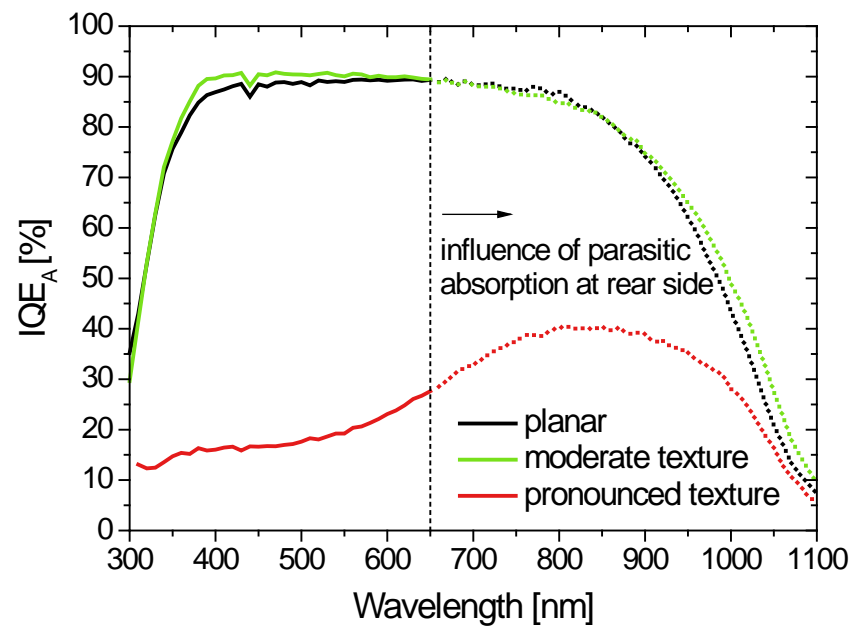

FIG. 6. Internal quantum efficiency $\mathrm{IQE}_{\mathrm{A}}=\mathrm{EQE} / \mathrm{A}$ of solar cell devices fabricated on planar glass, the moderate and the pronounced substrate texture. The dotted lines indicate the wavelength range in which the $\mathrm{IQE}_{\mathrm{A}}$ values are overestimated due to parasitic absorption.

Table I lists the maximum and average values along with the respective standard deviation of the open circuit voltage $V_{\text {oc }}$, the short circuit current density $J_{\mathrm{sc}}$, and the pseudo fill factor $p F F$ determined by $\operatorname{Sunc}_{\mathrm{oc}}$ and $\mathrm{EQE}$ measurements respectively. In addition the resulting efficiency potential $\eta_{\text {pot }}$ is tabulated which has been determined by taking the respective maximum values of the $V_{\mathrm{oc}}, J_{\mathrm{sc}}$, and $p F F$ into account. The number of available measurements taken into account for the calculation of the respective the average value und standard deviation is listed in brackets in Table I. While the $V_{\text {oc }}$ values obtained on the moderate texture, with a maximum of $616 \mathrm{mV}$, are on the same level as on planar reference substrates, solar cell devices on the pronounced texture exhibit strongly reduced $V_{\text {oc }}$ values featuring a maximum $V_{\text {oc }}$ of $539 \mathrm{mV}$. A comparable reduction of the $V_{\text {oc }}$ on this type of texture has already been observed in the case of a p-doped Si absorber layer. ${ }^{8}$ Similarly the $J_{\text {sc }}$ is significantly lower when performing the LPC process on the pronounced texture: The maximum and average $J_{\mathrm{sc}}$ values are 
reduced by a factor 2.6 in comparison to solar cells on planar substrates. In the case of the moderate substrate texture the maximum $J_{\mathrm{sc}}$ of $27.4 \mathrm{~mA} / \mathrm{cm}^{2}$ slightly exceeds the respective value on planar glass of $27.0 \mathrm{~mA} / \mathrm{cm}^{2}$. However, the average $J_{\mathrm{sc}}$ values were with $25.2 \pm 1.1 \mathrm{~mA} / \mathrm{cm}^{2}$ (moderate texture) and $25.3 \pm 1.2 \mathrm{~mA} / \mathrm{cm}^{2}$ (planar) on a comparable level. The fact that despite the comparable material quality and the absorption enhancement no significant increase of the $J_{\mathrm{sc}}$ can be observed for the solar cell on the moderate substrate texture as opposed to the planar sample can be explained by a slightly higher thickness of the $\mathrm{SiN}_{\mathrm{x}}$ antireflection coating in the case of the moderate substrate texture leading to additional reflection losses between $350 \mathrm{~nm}$ and $550 \mathrm{~nm}$ (see absorption spectra in Figure 5). The resulting efficiency potential $\eta_{\text {pot }}$ amounts to $13.2 \%$ in the case of the moderate substrate texture being slightly higher than the respective value for the planar substrate of $13.0 \%$, while the efficiency potential of the solar cell device on the pronounced substrate texture is with $4.3 \%$ significantly reduced.

TABLE 1. Average and maximum values and corresponding standard deviation of the open circuit voltage $V_{\text {oc }}$, the short circuit current density $J_{\mathrm{sc}}$, and the pseudo fill factor $p F F$ of solar cell devices realized on the moderate and the pronounced substrate texture and on planar glass. In addition the respective efficiency potential $\eta_{\text {pot }}$ is listed. The number of measurements taken into account is put in parentheses.

\begin{tabular}{lccccccc}
\hline Type & $\begin{array}{c}\overline{V_{o c}} \\
(\mathrm{mV})\end{array}$ & $\begin{array}{c}\text { max. } V_{\mathrm{oc}} \\
(\mathrm{mV})\end{array}$ & $\begin{array}{c}\overline{J_{s c}} \\
\left(\mathrm{~mA} / \mathrm{cm}^{2}\right)\end{array}$ & $\begin{array}{c}\text { max. } J_{\mathrm{sc}} \\
\left(\mathrm{mA} / \mathrm{cm}^{2}\right)\end{array}$ & $\begin{array}{c}\overline{p F F} \\
(\%)\end{array}$ & $\begin{array}{c}\text { max. } p F F \\
(\%)\end{array}$ & $\begin{array}{c}\eta_{\text {pot }} \\
(\%)\end{array}$ \\
\hline Planar & $599 \pm 12(6)$ & 615 & $25.3 \pm 1.2(12)$ & 27,0 & $72.4 \pm 4.7(6)$ & 78.2 & 13.0 \\
moderate texture & $598 \pm 11(12)$ & 616 & $25.2 \pm 1.1(16)$ & 27,4 & $73.7 \pm 3.5(12)$ & 78.2 & 13.2 \\
pronounced texture & $484 \pm 52(4)$ & 539 & $9.7 \pm 0.5(7)$ & 10,4 & $65.9 \pm 7.0(4)$ & 76.1 & 4.3 \\
\hline \hline
\end{tabular}

\section{DISCUSSION}

The above presented results reveal that the geometry of the substrate texture not only determines the optics of the resulting structured Si thin film but also strongly impacts the structural and electrical material properties: Si thin films on the pronounced texture provide excellent light harvesting especially in the NIR wavelength range enabling a $J_{\mathrm{sc} \text {,max }}$ of $36.3 \mathrm{~mA} / \mathrm{cm}^{2}$ even though the glass surface was missing an antireflection coating. However, the high aspect ratio texture also leads to an increased density of structural defects and a reduced solar cell performance compared to planar reference layers. Vice versa, Si layers on the moderate texture feature a high structural quality and a solar cell performance comparable to Si layers on planar substrates but yield only a slight absorption enhancement. Thus, the substrate textures investigated in this work define a parameter range concerning the respective feature height in which an optimal texture allowing a balance between light harvesting and material quality is to be expected.

The observed degradation of the solar cell parameters in the case of the pronounced substrate texture could be in principle due to both a reduced bulk diffusion length and enhanced recombination at the structured $\mathrm{Si} / \mathrm{SiO}_{\mathrm{x}}$ interface. The $\mathrm{Si}$ surface area enlargement at this interface which roughly amounts to a factor of 1.7 leads to an increased surface recombination current compared to a planar substrate. This can be taken into account by introducing an effective surface recombination velocity $S_{\text {eff }}$ according to $S_{\text {eff }}=K * S$, where $K$ represent the surface area enlargement and $S$ the surface recombination 
velocity. ${ }^{19}$ Haschke et al. determined an upper limit of the recombination velocity at the $\mathrm{Si} / \mathrm{SiO}_{\mathrm{x}}$ interface of $S=500 \mathrm{~cm} / \mathrm{s}$ for an n-doped LPC Si thin film on planar glass. ${ }^{1} 1 \mathrm{D}$ numerical simulations using the software AFORS-HET ${ }^{20}$ were performed to estimate the effect of the surface area enlargement. The results indicate that the severe reduction of the quantum efficiency cannot solely be explained by the surface area enhancement. Considering the enhanced density of structural defects observed in our experiments and the fact that dislocations in Si are known to act as recombination centers ${ }^{23-26}$, we conclude that a reduction of the diffusion length due to bulk defects is the dominant mechanism in this case.

Poor solar cell performance caused by an increased oxygen incorporation resulting from an enhanced film porosity on the high aspect ratio texture as it was reported by Merkel et al. for amorphous Si thin film precursor layers can be ruled out in the case of nc-Si precursors. Secondary ion mass spectroscopy measurements of LPC Si thins films on a $\mathrm{SiO}_{\mathrm{x}} / \mathrm{SiC}_{\mathrm{x}}$ intermediate layer stack, being comparable to the Si thin films analyzed in this study, yield with $2 \times 10^{17} \mathrm{~cm}^{-3}$ for both the pronounced texture and the planar substrate a comparable oxygen concentration. ${ }^{27}$ The increased density of dislocations observed in the Si thin film on the pronounced texture implies an enhanced thermal stress during the cooling phase after the solidification exceeding the critical resolved shear stress (CRSS) of Si. Lateral crystal growth is expected at low supercooling of the melt of about $50{ }^{\circ} \mathrm{C}-200{ }^{\circ} \mathrm{C}$ below the melting point of $\mathrm{Si}^{28}{ }^{28}$ In this range the CRSS of solid Si amounts to $2-3 \times 10^{7} \mathrm{dyn} / \mathrm{cm}^{2} .{ }^{29}$ The enhanced thermal stress could be explained as follows: As a first approximation the layer stack on the moderate substrate texture can be considered as a planar layer system. For this type of model system thermal stress can build up only parallel to the interface planes or the substrate surface respectively. In direction normal to the layer interface the system can relax. In contrast, for a high aspect ratio structured layer system with nearly vertical sidewalls, as it is the case for the pronounced texture, thermally induced stress states can build up also in the direction normal to the layer interfaces, e.g. in a silicon volume between two adjacent vertical sol-gel features.

The high open circuit voltages of above $600 \mathrm{mV}$ and the $\mathrm{IQE}_{\mathrm{A}}$ peak exceeding $90 \%$ achieved on the basis of Si thin-films on the moderate texture demonstrate that on nanoimprint patterned sol-gel high quality state of the art LPC Si thin films can be realized. The challenge on the way towards highly efficient LPC Si thin-film solar cells on tailored micro- and nanopatterned surfaces now consists of improving the antireflection and light trapping properties by increasing the surface roughness or structure height respectively and at the same time maintain the excellent Si material quality. To achieve this further work is needed to identify the appropriate parameters of the texture geometry, such as sidewall angle, surface roughness/structure height and filling ratio for optimal crystal growth. 


\section{SUMMARY}

We prepared double side textured crystalline Si thin-films on nanoimprint patterned sol-gel glass substrates by e-beam induced liquid phase crystallization and studied the correlation of the substrate texture with the optical, structural and electrical properties of the respective Si thin-films. As model systems we used a u-shaped square lattice pattern with a valleyto-peak height of $1.0-1.3 \mu \mathrm{m}$ and a pitch of $2 \mu \mathrm{m}$ as well as a random pattern exhibiting a surface roughness of $45 \mathrm{~nm}$ and characteristical lateral dimensions of 1-2 $\mu \mathrm{m}$. Si thin films on the pronounced periodic texture allow for excellent light trapping, while the respective thin films on the low-surface roughness texture show only a slight absorption enhancement in the near infrared. TEM analysis and defect etching revealed that Si thin-films crystallized on the pronounced periodic texture exhibit an increased density of structural defects compared to Si thin-films on the moderate random texture. Solar cells prepared on the pronounced periodic texture exhibit a reduced $V_{\text {ос }}$ and quantum efficiency compared to reference cells on planar glass. In contrast, solar cells realized on the low surface roughness random texture yield state of the art open circuit voltages exceeding $600 \mathrm{mV}$ and internal quantum efficiency peak values of above $90 \%$ being comparable to the respective parameters of planar reference solar cells. The corresponding efficiency potential amounts to $13.2 \%$. In conclusion, the results of this study demonstrate that liquid phase crystallization on patterned sol-gel/glass substrates is capable of achieving high quality Si thin films for PV applications.

\section{ACKNOWLEDGMENTS}

The authors thank C. Klimm, U. Bloeck, M. Wittig, M. Reiche, and P. Plocica for the specimen preparation and SCHOTT AG, Mainz, Germany for funding VP’s Ph.D.. The German Federal Ministry of Education and Research is acknowledged for funding the research activities of the Nano-SIPPE group within the program NanoMatFutur (No. 03X5520).

\section{REFERENCES}

${ }^{1}$ J. Haschke, D. Amkreutz, L. Korte, F. Ruske, B. Rech, Sol. Energy Mater. Sol. Cells 128, 190 (2014).

${ }^{2}$ O. Schultz, S. W. Glunz, G. P. Willeke, Prog. Photovoltaics 12, 553 (2004).

${ }^{3}$ D. Amkreutz, J. Haschke, S. Kühnapfel, P. Sonntag, B. Rech, IEEE Journal of Photovoltaics 4, 1496 (2014).

${ }^{4}$ O. Gabriel, T. Frijnts, S. Calnan, S. Ring, S. Kirner, A. Opitz, I. Rothert, H. Rhein, M. Zelt, K. Bhatti, J.-H. Zollondz, A. Heidelberg, J. Haschke, D. Amkreutz, S. Gall, F. Friedrich, B. Stannowski, B. Rech, R. Schlatmann, IEEE Journal of Photovoltaics 4, 1343 (2014).

${ }^{5}$ J. Dore, D. Ong, S. Varlamov, R. Egan, M. A. Green, IEEE Journal of Photovoltaics 4, 33 (2014).

${ }^{6}$ J. Müller, B. Rech, J. Springer, M. Vanecek, Sol. Energy 77, 917 (2004). 
${ }^{7}$ M. J. Keevers, T. L. Young, U. Schubert, M. A. Green, Proceedings of the $22^{\text {nd }}$ European Photovoltaic Solar Energy Conference, Milan, Italy, 2007, pp. 1783-1790.

${ }^{8}$ C. Becker, V. Preidel, D. Amkreutz, J. Haschke, B. Rech, Sol. Energy Mater. Sol. Cells 135, 2 (2015).

${ }^{9}$ F. Back, M. Bockmeyer, E. Rudigier-Voigt, P. Löbmann, J. Sol-Gel Sci. Technol. 66, 73 (2013).

${ }^{10}$ S. Kirner, M. Hammerschmidt, C. Schwanke, D. Lockau, S. Calnan, T. Frijnts, S. Neubert, A. Schöpke, F. Schmidt, J.-H.

Zollondz, A. Heidelberg, B. Stannowski, B. Rech, and R. Schlatman, IEEE Journal of Photovoltaics 4, 10 (2014).

${ }^{11}$ T. Sontheimer, C. Becker, F. Ruske, C. Klimm, U. Bloeck, S. Gall, O. Kunz, T. Young, R. Egan, J. Hüpkes, B. Rech, Proceedings of the $35^{\text {th }}$ IEEE Photovoltaic Specialists Conference, Honolulu, USA, 2010, pp. 614-619.

${ }^{12}$ E. Yablonovitch, T. Gmitter, J. Electrochem. Soc. 131, 2626 (1984).

${ }^{13}$ D. Amkreutz, J. Haschke, T. Häring, F. Ruske, B. Rech, Sol. Energy Mater. Sol. Cells 123, 13 (2014).

${ }^{14}$ D. Amkreutz, J. Müller, M. Schmidt, T. Hänel, T. F. Schulze, Prog. Photovoltaics 19, 937 (2011).

${ }^{15}$ B. Gorka, B. Rau, P. Dogan, C. Becker, F. Ruske, S. Gall, B. Rech, Plasma Process. Polym. 6, 36 (2009).

${ }^{16}$ J. Haschke, L.Jogschies, D.Amkreutz, L.Korte, B.Rech, Sol. Energy Mater. Sol. Cells 115, 7 (2013).

${ }^{17}$ T. Tiedje, E. Yablonovitch, G. D. Cody, B. G. Brooks, IEEE Trans. Electron Devices 31, 711 (1984).

${ }^{18}$ F. Secco d'Aragona, J. Electrochem. Soc. 119, 948 (1972).

${ }^{19}$ A. Bozzola, P. Kowalczewski, L.C. Andreani, J. Appl. Phys. 115, 094501 (2014).

${ }^{20}$ R.Stangl, C.Leendertz, J.Haschke, in Solar Energy (Ed. R.D. Rugescu), InTech, 2009, p. 14.

${ }^{23}$ N. A. Drozdov, A. A. Patrin, V. D. Tkachev, JETP letters 23, 597 (1976).

${ }^{24}$ J. Wong, J. L. Huang, S. Varlamov, M. A. Green, M. Keevers, Prog. Photovoltaics 20, 915 (2012).

${ }^{25}$ J. Wong, J. L. Huang. B. Eggleston, M. A. Green, O. Kunz, R. Evans, M. Keevers, R. J. Egan, J. Appl. Phys. 107, 123705 (2010).

${ }^{26}$ S. Steffens, C. Becker, D. Amkreutz, A. Klossek, M. Kittler, Y.-Y. Chen, A. Schnegg, M. Klingsporn, D. Abou-Ras, K. Lips, B. Rech, Appl. Phys. Lett. 105, 022108 (2014).

${ }^{27}$ J. J. Merkel, T. Sontheimer, B. Rech, C. Becker, J. Cryst. Growth 367, 126 (2013)

${ }^{28}$ G. Andrä, F. Falk, Phys. Stat. Sol. (C) 5, 3221 (2008).

${ }^{29}$ S. M. Hu, J. Appl. Phys. 49, 5678 (1978). 